\title{
Competências no trabalho: uma análise da produção científica brasileira
}

\author{
Hugo Pena Brandão \\ Universidade Corporativa Banco do Brasil e Fundação Getúlio Vargas
}

\begin{abstract}
Resumo
Este estudo objetivou revisar criticamente a produção científica nacional sobre competências no trabalho. Foram analisados relatos de pesquisas empíricas sobre o tema, publicados no período de 1996 a 2004 em importantes periódicos brasileiros das áreas de Psicologia e Administração. Buscando caracterizar essas investigações, foram discutidos os enfoques teóricos utilizados pelos autores, os propósitos e as opções metodológicas de suas pesquisas, os instrumentos de coleta de dados e os procedimentos de análise utilizados, entre outros aspectos. Foram discutidos também lacunas e limitações das pesquisas, procurando-se revelar carências e questões relevantes para estudo, bem como apresentar recomendações sobre estratégias de investigação. Constatou-se a predominância de estudos que buscam identificar competências relevantes a determinados papéis ocupacionais, bem como daqueles que examinam a contribuição de processos de aprendizagem para o desenvolvimento de competências. Diante da carência de investigações empíricas sobre o tema, ao final é sugerida uma agenda para pesquisas futuras.
\end{abstract}

Palavras-chave: competências profissionais; diagnóstico de competências; comportamento organizacional

\begin{abstract}
Competencies at work: an analysis of Brazilian scientific papers. This paper aimed to review the Brazilian scientific studies on competencies at work that were published between 1996 and 2004 in important Brazilian journals from the areas of Psychology and Business Administration. Empirical studies on the subject were identified and systematically analyzed, characterizing these inquiries, the theoretical approaches adopted by the authors, their intentions and methodological options used, the instruments of data collection and the procedures of analysis, among other aspects. Problems and limitations of the inquiries were discussed, aiming to disclose gaps and relevant questions for study, as well as presenting recommendations on research strategies. It has been evidenced the predominance of studies that attempted to identify relevant competencies to some occupational positions, as well as those that examined the contribution of learning processes for the development of competencies. Considering the lack of empirical inquiries on this subject, an agenda for future research is suggested in the end.
\end{abstract}

Keywords: professional competencies; competency mapping; organizational behavior

$\mathrm{C}$ om a emergência, na última década, da gestão por competências $^{1}$ (Brandão \& Guimarães, 2001; Dutra, 2004; Gonczi, 1999), grande discussão tem sido feita, tanto no meio acadêmico como no ambiente organizacional, em torno da noção de competência no trabalho, suas dimensões, implicações, antecedentes e conseqüentes (Le Boterf, 1999; McLagan, 1997; Ruas, Ghedine, Dutra, Becker, \& Dias, 2005; Zarifian, 1999).

Como competência constitui um conceito em evidência, complexo e multifacetado (Brandão \& Borges-Andrade, 2007; Gonczi, 1999), que possui variadas conotações e pode ser interpretado a partir de diferentes correntes teóricas (Dutra, 2004; Fleury \& Fleury, 2001; McLagan, 1997), torna-se relevante analisar e discutir as investigações realizadas sobre o tema.
Isso permitiria verificar, entre outros aspectos, se há evidências empíricas que sustentem certos pressupostos e construções teóricas, possibilitando compreender melhor a natureza da competência no trabalho, oferecer subsídios que aprimorem a intervenção organizacional e orientar a realização de novas pesquisas nesse campo de estudos.

O presente estudo possui como objetivo principal revisar criticamente as investigações empíricas realizadas no Brasil sobre competências no trabalho, procurando caracterizar a produção científica nacional acerca desse tema. Para tanto, foram analisadas as pesquisas empíricas publicadas no período de 1996 a 2004 nos principais periódicos brasileiros das áreas de Psicologia e Administração, procurando-se examinar modelos teóricos, métodos e resultados apresentados, bem como 
identificar lacunas e problemas de investigação. Espera-se, com esta revisão, oferecer contribuições ao debate teórico e prático em torno do assunto, bem como ensejar a realização de novas pesquisas.

Antes de revisar essa produção, é feita uma breve exposição sobre a natureza da competência no trabalho, sendo apresentados conceitos e proposições teóricas sobre o tema. Em seguida, descreve-se o método adotado nesta revisão e os resultados obtidos, incluindo uma síntese das pesquisas revisadas e a exposição de suas principais características e limitações. Ao final, são apresentadas conclusões e sugestões para investigações futuras, com questões relevantes para estudo e recomendações sobre estratégias e instrumentos de pesquisa.

\section{A noção de competência no trabalho}

No final da Idade Média, o termo competência pertencia essencialmente à linguagem jurídica. Dizia respeito à faculdade atribuída a uma pessoa ou a uma instituição para apreciar e julgar certas questões. Por extensão, a expressão veio a designar o reconhecimento social sobre a capacidade de alguém se pronunciar a respeito de determinado assunto e, mais tarde, passou a ser utilizada também para qualificar o indivíduo capaz de realizar certo trabalho, de exercer eficientemente um dado papel (Brandão \& Guimarães, 2001; Isambert-Jamati, 1997).

Nas últimas décadas, o interesse pelo tema estimulou o debate teórico e a realização de estudos organizacionais a respeito, sobretudo em razão do surgimento e difusão do modelo de gestão por competências, conforme relatam Brandão e Guimarães (2001), McLagan (1997) e Ruas et al. (2005), entre outros. Muitos autores procuraram criar definições próprias para o termo, chamando a atenção para seus variados aspectos. Gilbert (1978), por exemplo, destaca que a competência é expressa em função do desempenho ou comportamento da pessoa no trabalho, enquanto Durand (2000) dá ênfase a elementos que constituem a competência, ou seja, aos conhecimentos, habilidades e atitudes do indivíduo.

Por trás da proposta de Gilbert (1978) parece expressa a base teórica influenciada pelo movimento $S$ - $R$, a qual advoga que a compreensão do comportamento deve estar vinculada à investigação das relações entre estímulos $(\mathrm{S})$ e respostas $(\mathrm{R})$. A proposta de Durand (2000), por outro lado, parece influenciada pelo movimento $S-O-R$, pois parte da premissa de que essas relações, para serem plenamente compreendidas, precisam considerar o que ocorre no indivíduo $(\mathrm{O})$, que mediaria as relações entre estímulos $(\mathrm{S})$ e respostas $(\mathrm{R})$. Esse segundo movimento constitui a base sobre a qual estão sustentadas as abordagens cognitivistas e pressupõe que a interação da pessoa com o ambiente resulta em processos cognitivos ou na aquisição de conhecimentos, habilidades e atitudes (Brandão \& BorgesAndrade, 2007).

Não obstante a possibilidade de interpretar a competência de múltiplas maneiras (Brandão \& Guimarães, 2001; McLagan, 1997; Ruas et al., 2005), é possível perceber a existência de duas grandes correntes teóricas, conforme sugere Dutra (2004). A primeira, representada, sobretudo, por autores norteamericanos (Boyatzis, 1982; e McClelland, 1973, por exemplo), entende a competência como um conjunto de qualificações ou características subjacentes à pessoa, que permitem a ela realizar determinado trabalho ou lidar com uma dada situação. A segunda, representada principalmente por autores franceses (Le Boterf, 1999; e Zarifian, 1999, por exemplo), associa a competência não a um conjunto de atributos da pessoa, mas sim às suas realizações em determinado contexto, ou seja, àquilo que o indivíduo produz ou realiza no trabalho (Dutra, 2004).

Nos últimos anos, uma terceira vertente tem se destacado, na medida em que adota uma perspectiva integradora, buscando definir a competência a partir da junção de concepções das referidas correntes. Esse posicionamento é defendido por Gonczi (1999), para quem a competência tem o caráter de associar atributos pessoais ao contexto em que são utilizados, isto é, ao ambiente e ao trabalho que a pessoa realiza. A competência é entendida, então, não só como um conjunto de conhecimentos, habilidades e atitudes necessários para exercer certa atividade, mas também como o desempenho da pessoa em determinado contexto, em termos de comportamentos adotados no trabalho e realizações decorrentes (Carbone, Brandão, Leite, \& Vilhena, 2005).

Sob essa perspectiva, que está mais próxima do movimento $S-O-R$ e, portanto, de abordagens cognitivistas, competências podem ser entendidas como combinações sinérgicas de conhecimentos, habilidades e atitudes, expressas pelo desempenho profissional dentro de um contexto organizacional, que agregam valor a pessoas e organizações (Freitas \& Brandão, 2005). Essas combinações representariam a letra $O$, que sugere ser o indivíduo capaz de desenvolver competências que mediam as relações que seu comportamento $(\mathrm{R})$ estabelece com o ambiente (S). Segundo Carbone et al. (2005), embora existam diferentes visões sobre o tema, definições como essa parecem possuir aceitação mais ampla, tanto no meio acadêmico quanto no ambiente organizacional, na medida em que consideram as diversas dimensões do trabalho (cognitiva, psicomotora e afetiva) e associam a competência ao desempenho, no âmbito de uma estratégia ou de um contexto organizacional.

As competências profissionais ${ }^{2}$, então, são reveladas quando as pessoas agem frente às situações com as quais se deparam no trabalho (Zarifian, 1999). Servem como elo de ligação entre atributos individuais e a estratégia da organização (Prahalad \& Hamel, 1990). Assim, agregam valor, seja ele econômico ou social, a indivíduos e organizações, posto que contribuem para a consecução de objetivos organizacionais e expressam o reconhecimento social sobre a capacidade de pessoas, equipes e organizações, conforme ilustra a Figura 1.

Essa Figura, além de sugerir a complementaridade de conhecimentos, habilidades e atitudes, mostra que a aplicação desses três elementos no trabalho gera um desempenho profissional (Durand, 2000; Gonczi, 1999). Esse desempenho, por sua vez, é expresso pelos comportamentos que a pessoa manifesta e pelas conseqüências desses comportamentos, em termos de realizações ou resultados (Gilbert, 1978), de forma que o desempenho competente possui valor tanto para a pessoa que o produz quanto para a organização em que ela trabalha.

Freitas e Brandão (2005) comentam que a competência está associada à noção de aprendizagem, uma vez que resulta da aplicação de conhecimentos, habilidades e atitudes adquiridos 


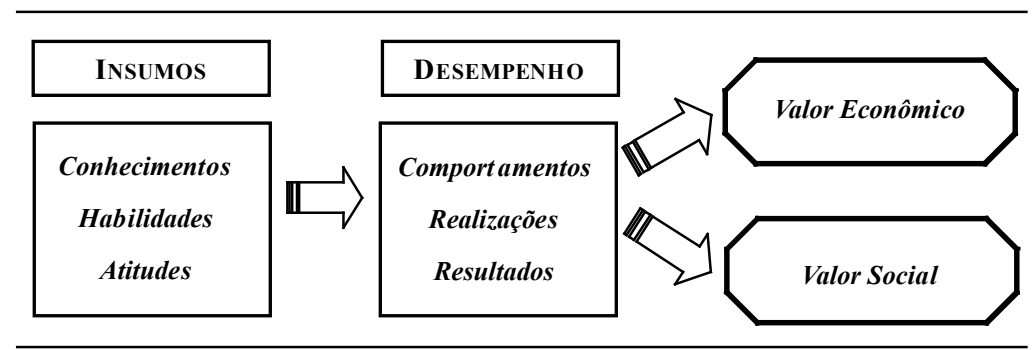

Figura 1. Componentes da competência profissional (adaptação de Fleury \& Fleury, 2001; e

Dutra, 2004)

pela pessoa em processos de aprendizagem, sejam eles naturais ou induzidos. Assim, a aprendizagem representaria o processo pelo qual se adquire a competência, enquanto o desempenho da pessoa no trabalho representaria uma expressão de suas competências, uma manifestação do que o indivíduo aprendeu ao longo de sua vida (Freitas \& Brandão, 2005).

A exemplo de outros objetos de estudo do comportamento organizacional, a competência é tida, ainda, segundo muitos autores (Brandão \& Guimarães, 2001; e Carbone et al., 2005, por exemplo), como um construto que se manifesta em diferentes níveis de análise, tendo em vista o pressuposto de que as organizações constituem sistemas multiníveis e seus resultados são influenciados por processos que ocorrem em cada nível e que interagem entre si, de forma interdependente (DeNisi, 2000; Kozlowski \& Klein, 2000).

Sob essa ótica, quando uma pessoa manifesta suas competências no trabalho, apresentando desempenho exemplar, pode introduzir mudanças em sua equipe e na organização, produzindo efeitos em diferentes níveis organizacionais (BorgesAndrade, Rocha, \& Puente-Palacios, 2002; DeNisi, 2000). De outro lado, a expressão das competências do indivíduo no trabalho pode ser influenciada tanto por atributos do próprio empregado (como os conhecimentos, habilidades e atitudes de que dispõe), quanto por características de sua equipe (como clima e suporte ao desempenho, por exemplo) e da organização (como cultura, normas e estrutura, entre outras), que podem atuar como facilitadoras ou restritoras da aplicação de competências no trabalho (Abbad, Freitas, \& Pilati, 2006; Brandão \& BorgesAndrade, 2007; DeNisi, 2000).

A competência constitui, portanto, um conceito complexo e multifacetado, que pode ser analisado sob diferentes perspectivas e está sujeito a ambigüidades. Como comentado, este estudo apresentará uma revisão crítica das pesquisas empíricas realizadas no Brasil sobre esse tema. Antes, porém, faz-se necessário expor o método adotado para realizar essa revisão.

\section{Método}

Para alcançar os objetivos propostos, realizou-se inicialmente uma pesquisa em quinze importantes periódicos das áreas de Psicologia e Administração, a saber: Estudos de Psicologia (Campinas); Estudos de Psicologia (Natal); Paidéia; Psico USF; Psico PUCRS; Psicologia, Ciência e Profissão; Psicologia em Estudo; Psicologia: Reflexão e Crítica; Psicologia: Teoria e
Pesquisa; Revista de Psicologia Organizacional e do Trabalho; Organizações \& Sociedade (UFBA); Revista de Administração Pública (FGV); Revista de Administração de Empresas (FGV); Revista Administração (USP); Revista de Administração Contemporânea. Buscou-se primeiro identificar e classificar artigos que constituíssem relatos de pesquisas empíricas no campo do comportamento organizacional. Esse levantamento preliminar foi realizado ao longo de vários semestres, por alunos do Programa de Pós-Graduação em Psicologia da Universidade de Brasília, entre os quais estava o presente autor.

Para escolha dos periódicos revisados, seguindo a mesma lógica de trabalho escolhida por Borges-Andrade e Meira (2003), foram utilizados como critérios a necessidade de o veículo ser indexado e de deter conceituação avaliativa bastante satisfatória (em âmbito nacional), conforme critérios definidos pela Fundação CAPES, do Ministério da Educação.

A partir desse levantamento inicial, procurou-se destacar aqueles artigos que versavam sobre competências, de forma a selecionar a amostra a ser revisada. A escolha desses artigos, por sua vez, obedeceu a critérios intencionais. Para compor a amostra, foi exigido que o texto: (a) abordasse o tema competências no trabalho; (b) constituísse um relato de pesquisa empírica sobre o assunto, abordando o fenômeno no nível do micro-comportamento organizacional; (c) tivesse sido publicado no período de 1996 a 2004, em uma das quinze revistas mencionadas anteriormente; e (d) fosse de autoria de brasileiro(s) e/ou descrevessem pesquisas realizadas no Brasil. Não foram incluídos artigos publicados em 2005, pois, por ocasião do levantamento de dados, alguns periódicos ainda não tinham publicado todas as suas edições daquele ano. Também não foram incluídos artigos que abordavam o tema somente no nível macro (da organização como um todo), os quais examinavam questões como, por exemplo, as competências organizacionais e suas relações com a estratégia corporativa, que se inserem no campo da Administração Estratégica, fugindo ao escopo da Psicologia Organizacional.

Uma vez identificados os artigos a serem revisados, estes foram sistematicamente analisados, procurando-se classificá-los quanto a diversos aspectos, como a formação e a instituição de vinculação dos autores, a natureza e a finalidade do estudo, o desenho da investigação, os instrumentos de coleta de dados e os procedimentos de análise, entre outras variáveis, a exemplo da classificação realizada por Borges-Andrade e Meira (2003). Fezse também uma análise crítica dos artigos, buscando examinar 
modelos teóricos, métodos e resultados, bem como identificar lacunas e limitações nas investigações revisadas.

Ao todo, foram selecionados onze artigos que atendiam aos referidos critérios. Esses trabalhos examinavam questões como a identificação de competências relevantes para contextos profissionais e papéis ocupacionais, o diagnóstico de necessidades de aprendizagem, as relações entre competências e desempenho, e efeitos da aprendizagem sobre o desenvolvimento de competências, entre outros aspectos, conforme exposto a seguir.

\section{Resultados e discussão}

\section{Síntese das pesquisas revisadas}

A maioria dos artigos revisados tinha como finalidade identificar competências profissionais - ou seus elementos constitutivos: conhecimentos, habilidades e atitudes (CHAs) - relevantes a determinados contextos, organizações ou papéis ocupacionais. Esse é o caso de Brandão, Guimarães e BorgesAndrade (2001), Bruno-Faria e Brandão (2003), Câmara e Sarriera (2001), Castro e Borges-Andrade (2004), Echeveste, Vieira, Viana, Trez, e Panosso (1999), Magalhães e BorgesAndrade (2001) e Trombeta (1997).

Brandão et al. (2001) procuraram identificar CHAs relevantes à qualidade do atendimento bancário. Tais variáveis, nesse caso, representariam elementos constitutivos da competência de prestar um atendimento de excelência ao cliente. Nesse estudo foram utilizados questionários estruturados para mensurar o grau de importância de 46 itens de competências, sendo a amostra constituída por 56 gerentes, 295 atendentes e 484 clientes de um banco público. $\mathrm{O}$ instrumento de pesquisa foi validado estatisticamente, tendo sido identificados 42 CHAs relevantes à qualidade do atendimento. Entre as variáveis consideradas mais importantes pelos respondentes estão: o conhecimento sobre produtos e serviços, a atitude de receptividade ao cliente e as habilidades de comunicação e de relacionamento interpessoal.

Echeveste et al. (1999) buscaram definir o perfil exigido do executivo frente à globalização de mercados, identificando conhecimentos, habilidades e atitudes que o tornam capaz de atuar nesse contexto. Utilizaram questionário para coleta de dados junto a 136 executivos de grandes empresas nacionais, os quais puderam atribuir graus de importância aos atributos dispostos no instrumento de pesquisa. Foram considerados mais importantes as atitudes de ética, integridade e proatividade, o conhecimento da empresa em que atua, e as habilidades de negociar, trabalhar em equipe, estabelecer relacionamento interpessoal e liderar.

Câmara e Sarriera (2001), por sua vez, procuraram identificar habilidades sociais, atitudes e outras características pessoais valorizadas por empregadores na cidade de Porto Alegre (RS), visando definir o perfil psicossocial de empregabilidade do jovem portoalegrense. Utilizando questionários estruturados, coletaram dados junto a 178 empresas das áreas de indústria, comércio e serviços. Nesse estudo, elementos constitutivos da competência - como atitudes e habilidades - foram analisados como atributos pessoais que contribuem, em alguma medida, para a empregabilidade da pessoa. Segundo a pesquisa, aspectos como o bom comportamento (respeito a normas e regras da empresa), estabilidade emocional, agilidade e habilidade de comunicação estão entre os atributos bastante desejados pelos empregadores.

Trombeta (1997) tentou identificar competências e outras características pessoais relevantes ao desempenho de professores universitários, segundo a percepção de estudantes de Psicologia. Utilizando instrumento que continha uma única questão aberta, solicitou a 79 alunos de uma faculdade privada que descrevessem as três características que julgassem mais importantes para que o professor fosse considerado bom. Ao analisar e classificar o conteúdo das respostas, verificou que, entre os aspectos relacionados à competência, a habilidade de expor conteúdos com boa didática, o conhecimento específico do conteúdo da disciplina ministrada e os conhecimentos gerais foram, respectivamente, os elementos mais mencionados. O estudo identificou, ainda, características de personalidade valorizadas pelos estudantes, como simpatia, bom humor e paciência, por exemplo.

Algumas pesquisas, além de revelar competências importantes para determinados contextos ou papéis ocupacionais, procuraram identificar em que medida os profissionais estudados dominavam tais competências, visando diagnosticar necessidades de aprendizagem. Em estudo realizado em um banco público, Magalhães e Borges-Andrade (2001), por exemplo, utilizaram questionários estruturados para avaliar, junto a uma amostra de 669 bancários (caixas-executivos e seus superiores imediatos), os graus de importância de 34 CHAs supostamente relevantes ao desempenho da função de caixa, bem como o domínio dos caixas em relação a esses itens. Entre os itens identificados como importantes estão a atitude de demonstrar interesse pelo trabalho, o conhecimento de rotinas de pagamento e recebimento e a habilidade para efetuar e conferir cálculos. Pela aplicação de uma fórmula específica ${ }^{3}$, esses autores identificaram, ainda, necessidades de treinamento dos caixas e examinaram as relações entre a auto e a heteroavaliação de necessidades. Verificaram que existe relação significativa entre auto e heteroavaliação, embora os supervisores tendam a apontar maiores necessidades de treinamento, em seus subordinados, do que estes em suas auto-avaliações.

Pesquisas semelhantes foram realizadas por BrunoFaria e Brandão (2003) e por Castro e Borges-Andrade (2004). Os primeiros procuraram evidenciar necessidades de desenvolvimento de competências relevantes a profissionais de treinamento e desenvolvimento (T\&D) de um órgão público do Distrito Federal. Utilizaram questionário estruturado, composto por 86 itens que descreviam conhecimentos, habilidades e atitudes supostamente relevantes a esses profissionais. A amostra, nesse caso, foi constituída por 66 servidores do órgão pesquisado, os quais atribuíram graus de importância e de domínio a cada item do instrumento. Entre as principais carências de aprendizagem identificadas para os servidores encontraram-se o conhecimento sobre técnicas de consultoria interna, a habilidade para operar sistemas informatizados (bancos de dados e planilhas de cálculo) e a atitude de demonstrar iniciativa.

Castro e Borges-Andrade (2004) buscaram diagnosticar 
necessidades de capacitação com base em competências relevantes ao cargo de assistente administrativo da Universidade de Brasília. A amostra foi constituída por 239 servidores da Universidade, os quais avaliaram a importância e o domínio de 64 CHAs dispostos no questionário. As maiores necessidades de capacitação identificadas recaíram sobre o conhecimento do idioma inglês, de leis e normativos, e sobre a habilidade de operar bancos de dados e planilhas eletrônicas. Nessas investigações, para diagnosticar prioridades de aprendizagem, também foram aplicadas fórmulas semelhantes àquela utilizada por Magalhães e Borges-Andrade (2001), já mencionada.

Os demais artigos (Bitencourt, 2004; Del Prette, Del Prette, Garcia, Silva, \& Puntel, 1998; Leite \& Porsse, 2003; e Okimoto, 2004) procuraram descrever e examinar, em diferentes contextos, processos de aprendizagem de competências e/ou resultados deles decorrentes.

Del Prette et al. (1998) investigaram a questão da competência na atuação do professor em sala de aula. Realizaram estudo de caso, no qual examinaram como uma professora do ensino fundamental transferia, para o contexto de sala de aula, as habilidades sociais que havia desenvolvido em um treinamento. As competências desejadas da professora, nesse caso, não foram descritas sob a forma de conhecimentos, habilidades e atitudes, mas sim por meio de referenciais de desempenho, ou seja, de comportamentos observáveis no trabalho. Para avaliar em que medida esse treinamento contribuiu para o desenvolvimento de competências da professora, esses autores registraram, por meio de vídeo-gravação em sala de aula, o desempenho dela antes e depois do curso. Em seguida, por meio de protocolos de análise, examinaram o conteúdo das filmagens e compararam a freqüência com que diversos comportamentos - os quais caracterizavam as competências profissionais - foram manifestos pela professora antes e depois do treinamento realizado. Os resultados indicaram importantes mudanças no comportamento da professora, evidenciando a contribuição do treinamento para o desenvolvimento das competências de controlar o tempo de execução de atividades didáticas, de supervisionar os alunos e de oferecer feedback verbal ao aprendiz, por exemplo.

Outro estudo que procurou avaliar a contribuição de uma intervenção (treinamento) para o desenvolvimento de competências profissionais foi realizado por Okimoto (2004). Essa autora utilizou-se de uma amostra de inspetores visuais de uma multinacional do ramo de eletroeletrônicos para identificar estratégias ou comportamentos visuais (oculomotores) que levavam a um melhor desempenho em atividades de inspeção visual da qualidade de produtos (detecção de defeitos como bolhas, estiramento, riscos, sujeira e falhas periféricas nos produtos produzidos). Depois, com base nos comportamentos identificados como mais eficazes, desenvolveu uma ação instrucional, baseada em tarefas de reconhecimento de falhas simuladas, para aprimorar competências relacionadas à acuidade visual. Comparando-se o desempenho dos inspetores antes e depois do treinamento oculomotor, foi possível evidenciar a contribuição dessa intervenção para o desenvolvimento de competências visuais, as quais implicaram na redução de erros durante a execução de tarefas de inspeção. A competência, nesse estudo, foi entendida como o comportamento manifesto no trabalho e seus efeitos, como, por exemplo, o percentual de produtos defeituosos detectados, o tempo gasto para reconhecimento de falhas e a correta identificação de irregularidades.

Pesquisa realizada por Bitencourt (2004) também procurou investigar práticas que promovem o desenvolvimento de competências. Por meio de estudo comparativo entre seis empresas (três brasileiras e três australianas), essa autora buscou identificar práticas de aprendizagem organizacional que podem contribuir para o desenvolvimento de competências gerenciais. Para coleta de dados, realizou entrevistas semi-estruturadas com profissionais das áreas de recursos humanos (RH) e de estratégia e gestores das empresas. Verificou que, nas empresas brasileiras, a competência gerencial é tratada com base em um perfil ideal de elementos constitutivos de competências, tendose como principal preocupação a redução das lacunas entre o perfil atual e o desejado. Nas empresas australianas, por sua vez, as competências referem-se à formação e à ação, refletindo a necessidade de tratá-las como práticas observadas no trabalho. Os gestores entrevistados destacaram, entre as práticas que contribuem para o desenvolvimento de suas competências, a adoção de modelos matriciais e de práticas de participação e feedback, nas empresas brasileiras, o relacionamento interpessoal (compartilhamento de conhecimentos) e a realização programas e parcerias com universidades, nas empresas australianas.

Leite e Porsse (2003), por sua vez, relataram a experiência de um banco público na identificação e disseminação de boas práticas gerenciais, como estratégia para compartilhamento do conhecimento e desenvolvimento de competências. Combinando observação participante, análise documental e entrevistas semi-estruturadas, esses autores investigaram o processo de identificação, seleção, validação e disseminação de 500 práticas gerenciais de excelência. Ao analisarem esse processo - o qual foi conduzido pelos próprios gestores da organização estudada - e seus efeitos, concluíram que o debate em torno das melhores práticas gerenciais constituiu estratégia para transformação de conhecimento tácito em explícito, permitindo o desenvolvimento e a alavancagem de competências profissionais. Esses autores comentam que, sob a perspectiva da abordagem multidimensional das competências, o processo por eles estudado revela que os gestores participantes desenvolveram uma nova e fundamental competência: a de registrar, extrair, disseminar e utilizar novos conhecimentos nas situações profissionais com as quais se deparam.

\section{Características da produção científica nacional}

No que se refere às correntes teóricas adotadas, a maioria das pesquisas revisadas (sete) descreveu as competências profissionais a partir de seus elementos constitutivos, ou seja, de CHAs, como é o caso de Castro e Borges-Andrade (2004) e Echeveste et al. (1999), por exemplo. Nesses artigos, a competência é entendida como um conjunto de atributos subjacentes ao indivíduo, que permitem a ele realizar determinado trabalho, concepção semelhante a de autores norteamericanos como Boyatzis (1982) e McClelland (1973). Dois artigos (Del Prette et al., 1998; e Leite \& Porsse, 2003), por outro lado, descreveram as competências sob a forma de referenciais 
de desempenho, isto é, de ações ou comportamentos observáveis no trabalho. Um outro (Okimoto, 2004) examinou a competência sob a perspectiva tanto de ações manifestas no trabalho e como de efeitos decorrentes delas, em termos de resultados produzidos, como conformidade, produtividade e qualidade do trabalho, por exemplo. Estes três últimos, então, aproximam-se da concepção de autores franceses como Le Boterf (1999) e Zarifian (1999), para quem a competência se refere às realizações do indivíduo em um dado contexto, ou seja, àquilo que a pessoa produz no trabalho (Dutra, 2004). Apenas um artigo (Bitencourt, 2004) descreve a adoção, por parte de participantes do estudo (gestores de empresas australianas), da concepção integradora defendida por Carbone et al. (2005) e Gonczi (1999), segundo a qual a noção de competência refere-se tanto à formação do indivíduo (ou aos CHAs de que dispõe) quanto à ação que este manifesta no trabalho.

Todos os artigos analisados parecem apoiados em abordagens cognitivistas e, portanto, no movimento S-O-R (Brandão \& Borges-Andrade, 2007), pois, mesmo naqueles em que as competências estudadas são operacionalmente descritas sob a forma de comportamentos ou ações observáveis, é assumido o pressuposto de que tais ações são influenciadas por processos cognitivos ou pelos CHAs aprendidos pelo indivíduo. Sobre isso, é importante mencionar que quatro artigos abordaram o tema competência em conjunto com outra categoria de estudos do comportamento organizacional: a aprendizagem e seus efeitos, como fizeram Bitencourt (2004) e Okimoto (2004). Estes procuraram evidenciar de que forma práticas de aprendizagem contribuíam para o desenvolvimento de competências, resultado que corrobora as proposições de Freitas e Brandão (2005), para quem a competência está associada à noção de aprendizagem, visto que ela resulta da aplicação de CHAs aprendidos pelo indivíduo.

Em relação aos veículos de publicação, seis artigos foram publicados em revistas da área de Administração e outros cinco em periódicos da área de Psicologia, evidenciando equilíbrio no número de publicações sobre o tema nas revistas dessas duas áreas de conhecimento. Esse equilíbrio se mantém quando o aspecto analisado é a última formação ou titulação dos autores. Entre as pesquisas revisadas, há treze autores e co-autores da área de Psicologia, onze da área de Administração e apenas dois de outras áreas de conhecimento (Sociologia e Engenharia de Produção). É relativamente comum profissionais com formação em Psicologia produzirem trabalhos em parceria com autores da área de Administração, como fizeram Bruno-Faria e Brandão (2003), o que talvez possa contribuir para aproximação entre essas duas áreas de conhecimento e para a análise de fenômenos sob diferentes perspectivas.

Quatro dos onze artigos revisados relatavam pesquisas produzidas em cursos de pós-graduação (três dissertações de mestrado e uma tese de doutorado). Os demais não possuíam vínculos dessa natureza ou não apresentavam essa informação. Oito artigos tinham seus autores vinculados a universidades federais, sendo quatro de autoria de professores e alunos de cursos de pós-graduação da Universidade de Brasília, entre os quais Brandão et al. (2001) e Magalhães e BorgesAndrade (2001). Isso sugere que a investigação empírica sobre competências tem sido valorizada por algumas universidades públicas que possuem programas de pós-graduação relacionados à área de organizações e trabalho.

Cinco artigos analisados foram publicados em 2003 e 2004, enquanto os demais foram produzidos no período de 1996 a 2002, o que sugere certo crescimento, nos últimos anos, do interesse de pesquisadores sobre o tema. O número de estudos empíricos publicados no Brasil sobre competências, no entanto, ainda é pequeno, em especial se comparado com o volume de discussões teóricas que têm sido feitas sobre o tema, conforme reportam Carbone et al. (2005) e Ruas et al. (2005), e com a quantidade de investigações empíricas realizadas sobre outras categorias de estudo do comportamento organizacional (Borges-Andrade $\&$ Meira, 2003).

No que se refere à natureza dos estudos, três artigos constituíam relatos de experiências ou práticas organizacionais, enquanto os outros oito relatavam pesquisas com desenho, sendo survey o tipo de investigação mais comum (sete artigos). Apenas um trabalho descrevia uma pesquisa-ação e nenhum deles tinha caráter experimental.

Quanto à abordagem metodológica, quatro artigos descreviam pesquisas quantitativas, três eram qualitativos e outros quatro combinaram instrumentos qualitativos e quantitativos na coleta de dados, evidenciando certo equilíbrio entre as opções metodológicas adotadas. Nos estudos de natureza quantitativa, os autores comentaram que a construção do instrumento foi precedida por pesquisa qualitativa, mas seus artigos relataram só os resultados quantitativos da investigação. Este é o caso de Câmara e Sarriera (2001) e de Magalhães e Borges-Andrade (2001), por exemplo. É interessante citar, também, que nos estudos qualitativos predominaram os autores da área de Administração, enquanto nas pesquisas essencialmente quantitativas prevaleceram autores da área de Psicologia. Quando o estudo era quali-quantitativo, por sua vez, geralmente havia autoria conjunta de profissionais dessas duas áreas de conhecimento, o que sugere ser a parceria entre autores da Psicologia e da Administração propícia à pluralidade metodológica e à análise de fenômenos sob diferentes perspectivas, como já comentado.

Com relação à natureza da amostragem, dez dos onze artigos revisados constituíam estudos amostrais, sendo que sete utilizaram amostras selecionadas em só uma organização e três obtiveram dados em duas ou mais organizações. Apenas um artigo (Del Prette et al., 1998) caracteriza-se como um estudo de caso. Todos os onze artigos revisados utilizaram dados primários, tendo somente um deles (Leite \& Porsse, 2003) se valido também de dados secundários, os quais foram fornecidos pela própria organização estudada.

Quanto aos instrumentos de pesquisa, quatro artigos utilizaram essencialmente questionários estruturados para coleta de dados, três combinaram a utilização de questionários com a realização de entrevistas e/ou de análises documentais (Bruno-Faria \& Brandão, 2003; Castro \& Borges-Andrade, 2004; e Echeveste et al., 1999), e um outro conjugou observação participante, entrevistas e análise de documentos (Leite \& Porsse, 2003). Dos três artigos restantes, um utilizou apenas entrevistas para coleta de dados (Bitencourt, 2004), um valeu-se 
de vídeo-gravação (observação) e de protocolos de análise (Del Prette et al., 1998) e um último mesclou observação com testes simulados (Okimoto, 2004). Tais resultados são característicos de pluralismo metodológico, ou seja, da utilização de variadas técnicas de pesquisa, o que constitui, para Borges e Pinheiro (2002), uma tendência na área de estudos organizacionais.

Em relação à análise dos dados, três artigos realizaram apenas análises descritivas e dois realizaram somente análises de conteúdo. Quatro artigos, por sua vez, conjugaram análises descritivas e inferenciais, enquanto outros dois combinaram análises de conteúdo e análises descritivas, caracterizando também certo pluralismo nos procedimentos de análise.

Finalmente, no que se refere ao setor pesquisado, predominaram os estudos realizados em organizações do setor público (seis artigos). Quatro artigos relataram pesquisas produzidas apenas em empresas privadas (Bitencourt, 2004; Câmara \& Sarriera, 2001; Okimoto, 2004; e Trombeta, 1997), um investigou empresas públicas e privadas (Echeveste et al., 1999) e nenhum relatou pesquisa feita em organização do terceiro setor. O segmento da economia mais investigado foi o terciário: sete artigos relataram pesquisas realizadas apenas em organizações do setor de serviços, três apresentaram estudos produzidos tanto no setor de serviços como em empresas industriais (Bitencourt, 2004; Câmara \& Sarriera, 2001; e Echeveste et al., 1999) e um relatou pesquisa realizada só no setor secundário (Okimoto, 2004).

\section{Lacunas nas pesquisas e problemas de investigação}

No que se refere às variáveis estudadas e suas relações, apenas um dos artigos revisados (Magalhães \& Borges-Andrade, 2001) procurou identificar, por meio de regressões estatísticas, variáveis preditoras do domínio de CHAs por parte da amostra estudada. Essa investigação, no entanto, ficou restrita à tentativa de verificar quais variáveis demográficas (como tempo de trabalho na empresa e na função, por exemplo) explicariam a necessidade de desenvolvimento de certas competências. Nenhum artigo procurou examinar se a aplicação de competências no trabalho tem como conseqüência a geração de valor, seja ele econômico ou social, para o indivíduo que manifesta a competência e para a organização em que ele atua.

Com isso, faltam pesquisas destinadas a investigar antecedentes e conseqüentes da expressão de competências no trabalho, de tal forma que importantes pressupostos teóricos, bastante mencionados pela literatura sobre o tema, ainda carecem de investigações empíricas. Este é o caso de suposições como, por exemplo: (a) o domínio de CHAs explica, em alguma medida, o desempenho no trabalho (Durand, 2000; Gonczi, 1999); (b) o suporte organizacional ao desempenho contribui para a expressão de competências profissionais (Abbad et al., 2006; Brandão \& Borges-Andrade, 2007); e (c) a expressão de competências influencia os resultados organizacionais (Carbone et al., 2005; DeNisi, 2000).

Outra questão que ainda precisa ser melhor analisada diz respeito às relações entre conhecimentos, habilidades e atitudes, elementos que, segundo alguns autores (Carbone et al., 2005; e Durand, 2000, por exemplo), teriam caráter complementar e interdependente, de tal forma que existiria uma influência mútua entre eles. De fato, em uma das pesquisas revisadas (Brandão et al., 2001), a análise fatorial das variáveis dispostas no instrumento (46 itens que descreviam CHAs) apresentou indícios de unidimensionalidade, indicando uma solução unifatorial. Outra investigação (Magalhães \& Borges-Andrade, 2001), no entanto, ao proceder análise semelhante, identificou um fator composto por atitudes e, outros, formados apenas por habilidades. Verificou, ainda, inexistirem correlações significativas entre esses fatores, o que sugere serem independentes. Faz-se necessário, portanto, investigar melhor as efetivas relações existentes entre CHAs, elementos referenciados na literatura como dimensões da competência.

A maioria das pesquisas que versam sobre a identificação de competências relevantes a determinadas funções (Del Prette et al., 1998; e Trombeta, 1997; por exemplo), bem como as que tratam do diagnóstico de necessidades de desenvolvimento de competências (Castro \& Borges-Andrade, 2004; e Magalhães \& Borges-Andrade, 2001, por exemplo), basearam seus levantamentos essencialmente na análise de tarefas ou de papéis ocupacionais. Parecem ter desconsiderado outros aspectos que podem determinar a relevância de certas competências, como a estratégia organizacional e tendências de introdução de novas tecnologias no trabalho e de mudanças na natureza das ocupações, o que constitui uma limitação. Apenas dois estudos (Brandão et al., 2001; e Bruno-Faria \& Brandão, 2003) explicitaram a utilização da estratégia da organização estudada como um elemento condicionante do diagnóstico de competências.

As pesquisas publicadas no Brasil, portanto, parecem restringir-se à identificação de competências importantes para responder a necessidades correntes, desconsiderando aquelas relevantes para o futuro. Também é importante, no entanto, a realização de diagnósticos que permitam às pessoas e organizações agir proativamente, no sentido de desenvolverem, no presente, competências que lhes serão requeridas apenas no futuro. Talvez isso pudesse ser equacionado, acrescentando-se mais uma variável - a importância futura das competências entre aquelas consideradas na identificação e priorização de necessidades de treinamento, de tal maneira que esse processo pudesse ter caráter não apenas corretivo, mas também proativo. Tentativas de identificar competências relevantes para o futuro já foram feitas por autores brasileiros (Brandão et al., 2002; Guimarães, Borges-Andrade, Machado, \& Vargas, 2001), mas essas pesquisas foram publicadas no exterior, de forma que ainda há carência de publicações no país que enfoquem este aspecto.

Ainda com relação às pesquisas sobre diagnóstico de necessidades de desenvolvimento de competências, é importante ressaltar que só uma delas (Magalhães \& Borges-Andrade, 2001) utilizou-se de heteroavaliação. As outras duas (Bruno-Faria \& Brandão, 2003; e Castro \& Borges-Andrade, 2004) utilizaram apenas auto-avaliações de competências, as quais estão mais sujeitas à leniência. Isso constitui outra limitação, pois, segundo Magalhães e Borges-Andrade (2001), em levantamentos dessa natureza, as avaliações podem diferir quanto à intensidade, dependendo de quem as julga, visto que os profissionais podem ter visões diferentes das percepções de seus superiores, pares ou clientes. Assim, tais diagnósticos seriam mais precisos se fossem 
realizados com base em avaliações por múltiplas fontes.

Embora diversos autores (Abbad et al., 2006; Brandão \& Borges-Andrade, 2007; e Le Boterf, 1999, entre outros) indiquem que características do ambiente de trabalho podem impor restrições à expressão de competências e ao desempenho profissional, nenhuma das investigações revisadas se propôs a examinar a influência de variáveis contextuais, pertencentes a níveis superiores da organização (características de equipes de trabalho e de unidades produtivas), sobre a competência das pessoas, no nível individual. Nenhum estudo investigou, também, como a expressão de competências no trabalho, por parte do indivíduo, pode introduzir mudanças em sua equipe e na organização, produzindo impactos em diferentes níveis organizacionais. Isso, além de constituir uma lacuna nas pesquisas sobre o tema, reforça o argumento de Kozlowski e Klein (2000), para quem, apesar de as organizações constituírem sistemas integrados e multiníveis, boa parte da ciência organizacional parece desconsiderar esse pressuposto, à medida que em geral se estuda cada nível isoladamente.

Embora seis artigos tenham utilizado questionários estruturados para coleta de dados quantitativos, apenas três validaram estatisticamente os instrumentos que aplicaram (Brandão et al., 2001; Echeveste et al., 1999; e Magalhães \& Borges-Andrade, 2001). Esse aspecto constitui uma limitação de algumas das pesquisas componentes da amostra, visto que, em estudos de natureza quantitativa, com a utilização de escalas de medidas, a validação estatística é importante para se verificar a validade e precisão dos instrumentos utilizados.

Convém ressaltar, ainda, que nenhum dos estudos foi realizado no setor primário da economia (agricultura), o que constitui outra lacuna nas pesquisas sobre o tema. É possível que isso tenha ocorrido devido à dificuldade de coletar de dados junto a sujeitos com baixa escolaridade, uma vez que, segundo Borges e Pinheiro (2002), os trabalhadores da agricultura estão tipicamente entre aqueles com menor grau de instrução. Mas não se deve desconsiderar a realização de estudos com trabalhadores de um setor que tem participação tão significativa na economia do país. Parece importante ampliar o espectro de setores da economia e de categorias profissionais que são objeto de estudos sobre competências no trabalho.

\section{Conclusões e recomendações}

Por meio de revisão bibliográfica sistemática nos principais periódicos nacionais das áreas de Psicologia e Administração, este estudo identificou e analisou relatos de pesquisas empíricas sobre o tema competências no trabalho, publicados no período de 1996 a 2004.

Essa revisão permitiu caracterizar a produção científica nacional sobre o assunto, e analisar os enfoques teóricos utilizados pelos autores, os propósitos e as opções metodológicas de suas pesquisas, os instrumentos de coleta de dados e procedimentos de análise mais comumente utilizados, as áreas de formação dos autores, os tipos de organização e os setores da economia estudados, entre outros importantes aspectos.

Em geral, constatou-se a predominância do estudo da competência a partir de seus elementos constitutivos, ou seja, de conhecimentos, habilidades e atitudes. São mais comuns as pesquisas que buscam identificar competências relevantes a certos papéis ocupacionais, bem como aquelas que examinam a contribuição de processos de aprendizagem para o desenvolvimento de competências. A maioria dos estudos analisados relatava pesquisas com desenho, sendo survey o tipo mais comum. Os resultados sugerem também a existência de pluralismo metodológico, ou seja, a utilização e combinação de variadas técnicas de pesquisa.

Foram identificados e discutidos também lacunas e limitações nas pesquisas revisadas, procurando-se revelar carências e questões relevantes para estudo, bem como recomendações de estratégias de investigação. Os resultados indicam que o tema ainda carece muito de investigações empíricas. Entre outros aspectos, parece fundamental a realização de mais estudos sobre a natureza da competência, em especial para verificar empiricamente as relações entre variáveis que são tidas como antecedentes e conseqüências da expressão de competências no trabalho. Organizações e pesquisadores poderiam, por exemplo, se dedicar a:

(a) investigar as efetivas relações entre conhecimentos, habilidades e atitudes, elementos tidos como componentes ou dimensões da competência profissional;

(b) identificar competências relevantes para o futuro, em função de tendências de introdução de tecnologias no trabalho e de mudanças na natureza das ocupações;

(c) identificar estímulos e barreiras ao desenvolvimento de competências no trabalho;

(d) analisar como as competências podem mediar as relações entre os estímulos presentes no ambiente organizacional e o comportamento adotado no trabalho;

(e) investigar que características do contexto de trabalho, da equipe e da organização podem restringir ou facilitar a expressão de competências profissionais;

(f) verificar como a expressão de competências no trabalho, por parte do indivíduo, pode introduzir mudanças em sua equipe e na organização, ou seja, examinar como a competência se propaga da pessoa para outros níveis organizacionais;

(g) utilizar a avaliação por múltiplas fontes no diagnóstico de competências, visando aumentar a precisão das estimativas sobre a relevância e o domínio de competências;

(h) realizar investigações sobre competências relevantes a categorias profissionais ainda pouco estudadas, sobretudo no setor primário da economia; e

(i) examinar se a aplicação de competências no trabalho gera valor, seja ele econômico ou social, para o indivíduo e para a organização em que ele atua.

A principal limitação deste trabalho diz respeito ao processo de levantamento dos artigos publicados sobre o tema. Como diferentes alunos de Pós-Graduação em Psicologia da Universidade de Brasília auxiliaram nesse levantamento, em diferentes períodos letivos, pode ser que algum pesquisador não tenha precisado corretamente a identificação de artigos que tivessem a competência ou seus elementos constitutivos como variáveis estudadas. Assim, se algum artigo foi indevidamente desconsiderado, sua ausência pode ter gerado vieses nos resultados desta pesquisa, o que constitui uma limitação a ser 
superada por estudos posteriores.

De qualquer forma, embora de abrangência limitada, esta pesquisa traz contribuições para a área, identifica lacunas e indica caminhos para estudos futuros. Tratando-se de trabalho sobre um tema em evidência e cujos pressupostos ainda carecem de investigações empíricas, espera-se ter oferecido contribuições ao debate teórico e prático em torno do assunto, bem como ensejado a realização de novas pesquisas.

\section{Agradecimento}

O autor agradece as observações e recomendações oferecidas por dois anônimos revisores, as quais contribuíram significativamente para o aprimoramento deste texto.

\section{Referências}

Abbad, G., Freitas, I. A., \& Pilati, R. (2006). Contexto de trabalho, desempenho competente e necessidades em TD\&E. In J. E. Borges-Andrade, G. Abbad, \& L. Mourão (Orgs.), Treinamento, desenvolvimento e educação em organizações e trabalho: fundamentos para a gestão de pessoas (pp. 231254). Porto Alegre: Artmed.

Bitencourt, C. C. (2004). A gestão de competências gerenciais e a contribuição da aprendizagem organizacional. Revista de Administração de Empresas, 44(1), 58-69.

Borges, L. O., \& Pinheiro, J. Q. (2002). Estratégias de coletas de dados com trabalhadores de baixa escolaridade. Estudos de Psicologia, 7(Número Especial), 53-63.

Borges-Andrade, J. E., \& Meira, M. (2003). As pesquisas sobre comportamento organizacional no Brasil [Resumo]. In Associação Nacional de Pesquisa e Pós-graduação em Psicologia (Org.), III Congresso Norte-Nordeste de Psicologia. Resumos (v. 1, p. 386). João Pessoa: Autor.

Borges-Andrade, J. E., Rocha, K. P., \& Puente-Palacios, K. E. (2002). Impacto de informações nas dimensões motivacionais, de capacidade e de desempenho dos indivíduos e das suas organizações [Resumo]. In Associação Nacional de Pós-Graduação e Pesquisa em Administração (Org.), XXVI Encontro da Associação Nacional dos Programas de Pós-graduação em Administração. Resumos (p. 397). Salvador: Autor.

Boyatzis, R. E. (1982). The competent management: a model for effective performance. Nova York: John Wiley.

Brandão, H. P., \& Borges-Andrade, J. E. (2007). Causas e efeitos da expressão de competências no trabalho: para entender melhor a noção de competência. Revista de Administração Mackenzie, no prelo.

Brandão, H. P., \& Guimarães, T. A. (2001). Gestão de competências e gestão de desempenho: tecnologias distintas ou instrumentos de um mesmo constructo? Revista de Administração de Empresas, 41(1), 08-15.

Brandão, H. P., Guimarães, T., \& Borges-Andrade, J. E. (2001). Competências profissionais relevantes à qualidade no atendimento bancário. Revista de Administração Pública, 35(6), 61-81.

Brandão, H. P., Guimarães, T. A., \& Borges-Andrade, J. E. (2002). Competências emergentes na indústria bancária. Revista Comportamento Organizacional e Gestão, 8(2), 173-190.

Bruno-Faria, M. F., \& Brandão, H. P. (2003). Competências relevantes a profissionais da área de T\&D de uma organização pública do Distrito Federal. Revista de Administração Contemporânea, 7(3), 35-56.

Câmara, S. G., \& Sarriera, J. C. (2001). Critérios de seleção para o trabalho de adolescentes-jovens: perspectiva dos empregadores. Psicologia em Estudo, 6(1), 77-84.

Carbone, P. P., Brandão, H. P., Leite, J. B., \& Vilhena, R. M. (2005). Gestão por competências e gestão do conhecimento. Rio de Janeiro: Fundação
Getúlio Vargas.

Castro, P. M. R., \& Borges-Andrade, J. E. (2004). Identificação das necessidades de capacitação profissional: o caso dos assistentes administrativos da Universidade de Brasília. Revista de Administração da USP, 39(1), 96108.

Del Prette, Z. A. P., Del Prette, A., Garcia, F. A., Silva, A. T. B., \& Puntel, L. P. (1998). Habilidades sociais do professor em sala de aula: um estudo de caso. Psicologia: Reflexão e Crítica, 11(3), 591-603.

DeNisi, A. S. (2000). Performance appraisal and performance management: a multilevel analysis. In K. J. Klein, \& S. W. J. Kozlowski (Orgs.), Multilevel theory, research and methods in organizations: foundations, extensions and new directions (pp. 121-156). San Francisco: Jossey-Bass.

Durand, T. (2000). L'alchimie de la compétence. Revue Française de Gestion, $127,84-102$.

Dutra, J. S. (2004). Competências: conceitos e instrumentos para a gestão de pessoas na empresa moderna. São Paulo: Atlas.

Echeveste, S., Vieira, B., Viana, D., Trez, G., \& Panosso, C. (1999). Perfil do executivo no mercado globalizado. Revista de Administração Contemporânea, 3(2), 167-186.

Fleury, A., \& Fleury, M. T. (2001). Estratégias empresariais e formação de competências: um quebra-cabeça caleidoscópico da indústria brasileira. São Paulo: Atlas.

Freitas, I. A., \& Brandão, H. P. (2005). Trilhas de aprendizagem como estratégia para desenvolvimento de competências [Resumo]. In Associação Nacional de Pós-graduação e Pesquisa em Administração (Org.), XXIX Encontro da Associação Nacional dos Programas de Pós-graduação em Administração. Resumos (p. 441). Brasília: Autor.

Gilbert, T. F. (1978). Human competence: engineering worthy performance. Nova York: McGraw-Hill.

Gonczi, A. (1999). Competency-based learning: a dubious past - an assured future? In D. Boud \& J.Garrick (Orgs.), Understanding learning at work (pp. 180-194). Londres: Routledge.

Guimarães, T. A., Borges-Andrade, J. E., Machado, M. S., \& Vargas, M. R. (2001) Forecasting core competencies in an R\&D Environment. $R \& D$ Management Review, 31(3), 249-255.

Heene, A., \& Sanchez, R. (1997). Competence based strategic management. Chichester, Reino Unido: Wiley.

Isambert-Jamati, V. (1997). O apelo à noção de competência na revista L'orientation scolaire et profissionelle: da sua criação aos dias de hoje. In F. Ropé, \& L. Tanguy (Orgs.), Saberes e competências: o uso de tais noções na escola e na empresa (pp. 103-134). Campinas: Papirus.

Kozlowski, S. W. J., \& Klein, K. J. (2000). A multilevel approach to theory and research in organizations: contextual, temporal and emergent processes. In K. J. Klein, \& S. W. J. Kozlowski (Orgs.), Multilevel theory, research and methods in organizations: foundations, extensions and new directions (pp. 03-90). San Francisco: Jossey-Bass.

Le Boterf, G. (1999). Competénce et navigation professionnelle. Paris: Éditions d'Organisation.

Leite, J. B. D., \& Porsse, M. C. S. (2003). Competição baseada em competências e aprendizagem organizacional: em busca da vantagem competitiva. Revista de Administração Contemporânea, 7(Edição Especial), 121-144.

Magalhães, M. L., \& Borges-Andrade, J. E. (2001). Auto e hetero-avaliação no diagnóstico de necessidades de treinamento. Estudos de Psicologia (Natal), 6(1), 35-50.

McClelland, D. (1973). Testing for competence rather than intelligence. American Psychologist, 28(1), 1-14.

McLagan, P. (1997). Competencies: the next generation. Training \& Development, $51,40-47$.

Okimoto, M. L. R. (2004). Explicitação do conhecimento tácito: um estudo de caso no setor industrial. Revista de Psicologia Organizacional e do Trabalho, 4(1), 123-150.

Prahalad, C. K., \& Hamel, G. (1990). The core competence of the corporation. 
Harvard Business Review, 68(3), 79-93.

Ruas, R., Ghedine, T., Dutra, J. S., Becker, G. V., \& Dias, G. B. (2005).

$\mathrm{O}$ conceito de competência de $\mathrm{A}$ a $\mathrm{Z}$ : análise e revisão nas principais publicações nacionais entre 2000 e 2004 [Resumo]. In Associação Nacional de Pós-graduação e Pesquisa em Administração (Org.), XXIX Encontro da Associação Nacional dos Programas de Pós-graduação em Administração.
Resumos (p. 459). Brasília: Autor

Trombeta, L. H. P. (1997). Características do bom professor segundo a percepção de estudantes de Psicologia. Estudos de Psicologia (Campinas), 14(2), 71-74.

Zarifian, P. (1999). Objectif compétence: pour une nouvelle logique. Paris: Liaisons.

${ }^{1}$ Segundo Brandão e Guimarães (2001), a gestão por competências constitui um modelo gerencial que se propõe a orientar esforços para planejar, captar, desenvolver e avaliar, nos diferentes níveis da organização (individual, grupal e organizacional), as competências necessárias à consecução de seus objetivos.

${ }^{2}$ Alguns autores (Brandão \& Guimarães, 2001; e Heene \& Sanchez, 1997, por exemplo) classificam as competências como profissionais ou humanas (aquelas relativas a indivíduos) e como organizacionais (aquelas que constituem atributos da organização, e não de indivíduos isoladamente). Este artigo trata apenas da competência no nível individual, como uma unidade de estudo do micro-comportamento organizacional. Embora aqui se utilize a expressão competências profissionais para designar essa categoria de análise, é comum na literatura a adoção de outras denominações - como, por exemplo, competências pessoais, competências humanas e competências individuais - para expressar idéia similar.

${ }^{3} N=$ I $(4-\mathrm{D})$, onde $N$ representa a Necessidade ou Prioridade de Aprendizagem, $I$ refere-se ao grau de importância atribuído à competência, e $D$ ao grau em que profissional domina ou possui a competência (ver Magalhães \& BorgesAndrade, 2001)

Hugo Pena Brandão, doutorando em Psicologia Social, do Trabalho e das Organizações pela UnB, é pesquisador master na Universidade Corporativa Banco do Brasil e Professor da Fundação Getúlio Vargas (Núcleo de Brasília). Endereço para correspondência: SMDB Conjunto 12-B, Lote 3, Casa "C", Lago Sul; Brasília, DF; CEP 71680-122. Tel.: (61) 3366-5167. E-mail: hugopb@tba.com.br 